\title{
Dança como possibilidade de educação para Direitos Humanos: entendendo, discutindo e encenando o Holocausto
}

https://doi.org/10.11606/issn.1981-4690.v35i3p89-97

\section{Resumo}

O presente artigo tem como objetivo apresentar a dança como possibilidade de educação para direitos humanos. Trata-se de uma pesquisa qualitativa por meio de estudo observacional transversal descritivo por meio da análise documental de vídeos. O estudo tem como objeto a descrição do processo de educação, preparação, sensibilização e efetivação do Espetáculo Endless em Goiânia-Goiás. Por meio dos resultados foi possível verificar a potência da extensão universitária e da dança como forma de educação para direitos humanos. Foram analisados relatos de bailarinos, coreógrafo e coordenadora do projeto, além de imagens do ensaio e do espetáculo. Foi possível verificar, pelos relatos, que a dança inclusiva/ decolonial e a acessibilidade cultural, promoveu mudanças de paradigmas e consciência dos horrores do Holocauto e dos Direitos Humanos. As imagens dos ensaios e espetáculo também proporcionaram verificar a potência da dança para sensibilização e consciência da necessidade de Direitos Humanos. Concluímos que a experiência com o Endless permitiu que os envolvidos participassem de forma singular, múltipla, com suas eficiências e deficiência. O espetáculo lançou um olhar para o respeito pela diferença e diversidade comprovando a potência da dança como Educação para Direitos Humanos.

Palavras-Chave: Direitos Humanos; Dança; Diversidade; Educação.

\section{Introdução}

O preconceito, desrespeito à diversidade e falta de consciência da necessidade de dignidade humana é uma realidade da sociedade contemporânea possível de se notar em diversas situaçôes, relaçóes e açôes cotidianas. Os direitos humanos e diversidade muitas vezes são hostilizados com comentários como "O erro da ditadura foi torturar e não matar", "Eu sou favorável à tortura", "Morreram poucos. A PM tinha que ter matado mil", "Eu jamais ia estuprar você porque você não merece", "Foram quatro homens. A quinta eu dei uma fraquejada, e veio uma mulher", "prefiro que morra num acidente do que apareça com um bigodudo por aî", "filho começa a ficar assim meio gayzinho, leva um couro, ele muda o comportamento dele", "O afrodescendente mais leve lá pesava sete arrobas. Não fazem nada!", "Quem usa cota, no meu entender, está assinando embaixo que é incompetente”. Essas entre outras muitas frases com tom preconceituoso, machista, homofóbico e racista foram ditas em 2018. Foi nessa época e nesse contexto que aconteceu o trabalho descrito neste artigo.

Essas frases continuam recorrentes e podem tornar ainda mais comum o desrespeito ao entendimento que: "todos os seres humanos nascem livres e iguais em dignidade e direitos. São dotados de razão e consciência e devem agir em relação uns aos outros com espírito de fraternidade", como é defendido na Declaração Universal dos Direitos Humanos ${ }^{1}$.

Essa importante declaração surge em 1948, após a segunda guerra mundial e o holocausto, que foi considerado segundo LEvy e SzNAIDER 2 "a história do racismo na sua pior faceta ou como um crime contra a humanidade"2 (p. 262).

Estima-se que aproximadamente 6 milhões de
*Universidade Federal de Goiás, Goiânia, Goiás, GO, Brasil.

**Grupo Dançando com a Diferença,

Funchal, Portugal.

* * Universidade

Estadual de Goiás,

Goiânia, Goiás, GO,

Brasil. 
pessoas morreram durante o holocausto entre judeus, ciganos, eslavos, homossexuais, pessoas com deficiência, imigrantes, alcoólatras, pessoas com doenças mentais, testemunhas de Jeová, maçons, prisioneiros de guerra, políticos, entre outros. Dentre os mortos tiveram desde bebês até idosos, que eram mortos em câmaras de gazes, em grandes centros de concentração e em câmaras móveis em caminhões, também em fuzilamentos, em experiências médicas e em condições de mortes por fome, cansaço, frio, doenças e outras condiçóes inaceitáveis.

O holocausto e os horrores presenciados nesse momento impulsionaram a criação da Declaração Universal dos Direitos Humanos das Naçóes Unidas, em 10 de dezembro de 1948, resultado da "repugnância moral compartilhada por aqueles que advogavam contra o Holocausto"2 (p. 272).

As manifestaçóes hegemônicas da dança, como outras práticas da cultura corporal, vêm sendo tratada de forma excludente, que valoriza o "corpo com padrão europeu"3, com "modelo pedagógico repetitivo e diretivo" "4 que não respeita as diferentes formas de se movimentar, com "ênfase no repertório" 3 . Assim, com objetivo de tornar a dança mais inclusiva, que busca emancipação de todos os tipos de dominação e opressão, nesse sentido autoras das artes e das danças têm discutido formas de decolonialidade em suas práticas ${ }^{3,4}$.

As artes e a dança enquanto manifestação artística, passou por profundas transformações estéticas no século $\mathrm{XX}^{5}$, que tornaram possível a participação das pessoas com deficiência no universo cênico, este aspecto histórico é um dos argumentos teóricos que sustentaram a formulação do conceito da Dança Inclusiva, desenvolvido por BARRAL ${ }^{5}$ que reafirma a cada obra a sua posiçáo teórica, de que somente um produto com excelência artística poderá contribuir para que uma gradativa mudança na imagem social das pessoas com deficiência aconteça. Segundo BARRAL ${ }^{5}$, a temporalidade do conceito de Dança Inclusiva, prevista desde sua criação, é algo em que continuamos a experienciar, sem é claro questionar suas possibilidades de existência e visibilidades, este é um dos motivos da existência do Dançando com a Diferença, conforme entendimento do diretor do grupo, também a nossa a dança inclusiva, tem sua característica de ser um temporal, ou seja:

[...] quando os bailarinos com corpos diferentes forem aceitos em todas as companhias de dança pelas suas qualidades artísticas e esta diferença não for mais alvo de tantos estudos, atitudes incrédulas e/ou de condescendência dúbia, pensamos, teremos cumprido o nosso papel na procura de uma real inclusão destas pessoas no universo da dança e nesse momento o termo Dança Inclusiva poderá ser desprezado, ficando somente para os registos históricos - sintoma de plena aceitaçáo da unicidade na diversidade, pois de bailarinos se trata, que dançam com o corpo e não "apesar do corpo"s (p. 124).

Alicerçada por esta breve contextualização, essa pesquisa tem como objetivo discutir uma proposta de dança inclusiva e decolonial, como forma de inclusão de pessoas com deficiência, e de discussão sobre preconceito e educação para direitos humanos, levando para os palcos questóes complexas como o holocausto.

\section{Metódo}

Esse artigo apresenta uma pesquisa qualitativa, por meio de estudo observacional transversal descritivo. $\mathrm{O}$ estudo tem como objeto a descrição do processo de educação, preparação, sensibilização e efetivação do Espetáculo Endless, realizado em 2018 em Goiânia - Goiás, pelo projeto de extensão Diversus da Universidade Federal de Goiás, em parceria com o Projeto Dançando com a Diferença de Portugal, com apoio do Fundo de Arte e Cultura

do Estado de Goiás.

Para isso utilizaremos a análise documental de vídeos, sendo eles: História do Grupo de Dança Diversus $^{6}$, Material promocional do Espetáculo Endless em Portugal em 2012 $2^{7}$, documentário com depoimentos no Brasil em $2018^{8}$, vídeo promocional reportagem TV aberta de $2018^{9}$ e vídeo promocional reportagem TV fechada de $2018^{10}$. Para análise utilizaremos a Análise de conteúdo de BARDIN ${ }^{11}$. 


\section{Resultados}

O processo aqui descrito é originário de um projeto de extensão universitário que tem como foco na dança inclusiva, o mesmo surge em 2009 quando foi verificado que nos projetos de extensão na Faculdade de Educação Física e Dança da Universidade Federal de Goiás, apesar de ter mais de 800 pessoas participando das atividades, não havia nenhuma pessoa com deficiência incluída ${ }^{12}$. Assim nasce o projeto de extensão Dando Asas, que tem como objetivo a inclusão e autonomia das pessoas com deficiência nos mais de 25 projetos de extensão dessa instituição. Considerando ainda que as práticas aquáticas e a dança eram as atividades mais procuradas por essas pessoas ${ }^{5}$, desde então há uma atenção e desenvolvimento de atividades de dança com o olhar para a inclusão, e no ano de 2017 foi criado o Projeto de Extensão Dançando com a Diferença: arte, inclusão e comunidade, no qual surge o Grupo de Dança Diversus ${ }^{6}$.

A relação da extensão universitária e educação em direitos humanos torna os projetos mais inclusivos, educacionais e humanos.

$\mathrm{Na}$ extensão universitária, a inclusão dos direitos humanos no Plano Nacional de Extensão Universitária enfatizou o compromisso das universidades públicas com a promoção dos direitos humanos. A inserção desse tema em programas e projetos de extensão pode envolver atividades de capacitação, assessoria e realização de eventos, entre outras, articuladas com as áreas de ensino e pesquisa, contemplando temas diversos ${ }^{13}$ (p. 5).

Participaram do processo de preparação e do espetáculo aproximadamente 90 pessoas, envolvendo equipe de professores, filmagem, iluminação, som, apoio e 60 pessoas no palco como bailarinos, músicos, cantores e atores, entre eles a diversidade de gênero, geracional, de experiência na dança, nacionalidade (portugueses e brasileiros) e de deficiência/eficiência (motora, intelectual, visual e auditiva) estavam presentes ${ }^{9,10}$. Os ensaios foram orientados pelas práticas pedagógicas inclusivas, onde todos participaram das mesmas atividades, existiam ações com acessibilidade pedagógica, atitudinal, arquitetônica e comunicacional.

A coordenadora artística do projeto do espetáculo considera que a construçáo desse projeto foi pensada na perspectiva da acessibilidade cultural, diz que

o que é isso é trazer para o palco pessoas com e sem deficiência e também pensar na acessibilidade de quem vai assistir, fazer a fruição desse espetáculo toda a montagem dele teve esse aspecto da acessibilidade entáo o que as pessoas costumam receber para poder apreciar um espetáculo, se tem um programa, quais são outros tipos de programas acessíveis que estas pessoas precisam para assistir ${ }^{10}$.

Nas imagens enquanto a coordenadora artística do projeto falava aparecia pessoas com deficiência utilizando equipamentos de audiodescrição, programa com braile e representação do palco e dos artistas em cena em alto relevo e interpretação em libras realizada pelos próprios bailarinos em cena e em tela à frente da coreografia ${ }^{10}$.

O coreógrafo do Endless relatou que quando se fala de dança inclusiva se pensa na acessibilidade e inclusão para os espectadores, mas que nesse trabalho a acessibilidade foi pensada nos ensaios e no momento do espetáculo ${ }^{10}$, considerando-se e respeitando-se as diversidades visuais, auditivas, motoras e neurodiversidades.

Sobre a diversidade na dança e no processo descrito nesse artigo, a coordenadora artística do projeto do espetáculo relata:

A diferença é ser humano. O que constitui o ser humano, o que nos iguala é sermos diferentes. Então dançar com a diferença é pensar que cada um pode dançar com a sua particularidade, com a sua singularidade, contribuir com isso e náo com as questóes hegemônicas de corpo ou de estática de dança. Dançar com a diferença é dançar o que nos une, é celebrar a partir da singularidade de cada corpo, e pensar em uma estética que caiba essa diversidade ${ }^{8}$.

Danças como Ballet, Danças Gaúchas e dança de rua muitas vezes repetem práticas coloniais, que reforçam preconceitos e estereótipos presentes na sociedade ${ }^{3}$. As colonialidades na dança privilegiam a técnica, o virtuosismo, a repetição de sequências e a competição entre os colegas ${ }^{4}$. Para que a dança, ganhe contornos mais inclusivos é fundamental que se efetive práticas como a descrita neste trabalho por meio da decolonialidade da dança, propondo "formas outras de vivenciar a dança, também estaremos mudando essas relaçóes constituídas no modo de se fazer dança"4 (p. 11).

Quando se fala em dança inclusiva não se precisa abandonar a dança performance ou competitiva. Alguns grupos de dança inclusiva têm mostrado na Europa e no Brasil que é possível incluir 
pessoas com deficiência na dança e a estética, beleza, emoção e eficiência continuar presente ${ }^{3}$. $\mathrm{O}$ coreógrafo do espetáculo aqui apresentado, relata que além de realizar inclusão e acessibilidade das pessoas que vão assistir e das pessoas que dançam, o espetáculo Endless permite que os artistas com e sem deficiência dancem com tal beleza que outros coreógrafos que reconheçam e os desejem em seus trabalhos e grupos artísticos, isso pela eficiência que apresentam no palco $^{10}$.

\section{Preparando a cena: educação para direitos humanos}

A possibilidade de discussão e educação dos direitos humanos surge por meio do Espetáculo Endless, o qual foi criado por Henrique Amoedo, que é diretor do Grupo com a Diferença de Portugal, e participou ativamente da remontagem no Brasil em Goiânia. Segundo o coreógrafo do Endless esse termo significa "Sem fim" e teve como objetivo relembrar os horrores vividos no holocausto com milhóes de mortos ${ }^{8}$.

O espetáculo Endless foi sucesso na Europa e sua criaçáo acontece em 2011/2012 em um projeto europeu de "Aprendizagem ao longo da vida", em uma parceria com Alemanha, Polonia, Lituânia, Estônia e Portugal, teve viagens e visitas nos campos de concentração, principalmente de Auschwitz, a ideia é olhar para o holocausto como uma forma de conscientizar as pessoas como um evento atual, buscando a reflexão, para que não aconteça novamente ${ }^{8}$.

Em nível mundial sabe-se que o Holocausto eliminou não só judeus, ciganos, mas também pessoas com deficiências. Nesse período também foram eliminados todos aqueles que fossem suspeitos de ter hereditariedade de cegueira, surdez e deficiência mental ${ }^{14}$ (p.53).

O roteiro do Endless foi baseado nos horrores do Holocausto quando milhóes de pessoas foram eliminadas, a maioria delas por serem diferentes, e por terem alguma deficiência?.

O processo de preparação para o espetáculo Endless em Goiânia, se iniciou com sensibilização e ensaios em janeiro de 2018, com a visita do criador e coreógrafo português. Foram 15 dias intensos com palestras, rodas de conversa, apresentação de filmes, experiencias corporais e ensaios das cenas, onde os mais de 60 participantes brasileiros discutiram sobre o que o Holocausto significou no desrespeito aos direitos humanos, resultante de preconceitos como racismo, homofobia, capacitismo, machismo, entre outros, onde houve a morte de aproximadamente 6 milhóes de pessoas, sendo que entre estas estavam de 200 a 250 mil pessoas com deficiência, característica de vários dos artistas brasileiros que participaram desse processo.

Os ensaios foram de movimentaçóes que proporcionaram vivências corporais buscando sentir um pouco dos horrores que as pessoas viveram no holocausto (FIGURA 1). Por exemplo: vivenciar o movimento de flexionar os joelhos e permanecer até a exaustão teve como objetivo sensibilizar para as mortes que aconteceram com a exaustão aos trabalhos submetidos nos campos de concentração, vivenciar o sufoco da vivência dos corpos dos artistas apertados em um pequeno espaço onde estava a luz cênica proporcionou a sensibilização da falta de ar nas câmaras de gás, vivenciar ouvir sons de tiros e soltar o corpo ao chão nos fez pensar que esse som significou o último a ser ouvido pelas vítimas dos fuzilamentos.

O depoimento de uma bailarina do elenco do Endless mostra que essa preparação para o espetáculo e a própria dança são capazes de modificar e intensificar percepçóes sobre o que foi o holocausto:

Pensar a questão do holocausto por esse lugar do corpo que é um lugar bastante sensível, que é o caminho para as emoçôes, me dá outra percepção do que é o holocausto. Depois dessa experiencia com o próprio Henrique, de pensar essa preparação para o espetáculo, eu comecei a pesquisar documentários, ele fez indicações de filmes para a gente ir percebendo essas sensibilidades do que foi e colocando isso como memória corporal. Isso muda totalmente sua percepção em relação ao holocausto ${ }^{8}$.

Assim a Educação Física e a Dança puderam proporcionar nesse momento de preparação, junto com as palestras, rodas de conversa e reflexóes, vivências corporais que segundo os artistas ficarão marcados para o resto da vida ${ }^{8,9}$.

Educação em direitos humanos numa IES no campo da educação física envolve... a necessidade de um despir-se de uma cultura de exclusão, com a desconstruçáo de preconceitos e julgamentos, para inserir-se na construçáo de uma cultura de inclusão, equidade, motivação e pertencimento social $^{13}$ (p. 7). 



FIGURA 1 - Ensaios.

Um projeto de extensão em uma Faculdade de Educação Física e Dança, que tenha como foco a educação para direitos humanos e práticas inclusivas, pode trazer diversos benefícios como: formação de professores inclusivos e humanos; a experiência, relação e respeito entre participantes com e sem deficiência pode oferecer; diminuição das barreiras atitudinais e aumento da empatia; entre outras ${ }^{15}$.

\section{Vivenciando o holocausto: direitos humanos em espetáculo de dança}

Durante o espetáculo, por meio da dança inclusiva, foi possível visualizar a dança, a história, a emoção e a eficiência. Tivemos no palco diferentes corpos e muitos deles, como pessoas idosas, obesas, com deficiência, LGBTI+, pessoas negras entre outros sujeitos alvo de preconceitos na sociedade. O coreografo do espetáculo sobre esse processo relata que:

quando se fala de deficiência normalmente, ou das populaçốes que de alguma forma estão marginalizadas na sociedade, você só ouve os "nãos", você só ouve o que elas não conseguem fazer. Isso náo me interessa mais saber, isso eu já sei, isso as pessoas já sabem, a gente tenta ter outro olhar, e perceber o que elas conseguem para trazer de alguma forma esse melhor de cada um para cena ${ }^{8}$.

No início do documentário Endless 8 é possível ver alguns segundos das cenas com o resultado cênico do processo aqui descrito. O espetáculo se inicia antes do holocausto com a alegria da populaçáo em um show, mas as cenas vão se tornando mais tensas, passando das brincadeiras das crianças nas ruas para a atividade ginástica que tinha como objetivo tornar os corpos dóceis e eficientes. Culminando em uma cena que demonstra o início da barbárie com a representação da Colina das cruzes na Lituânia, que simboliza os entes das famílias que sumiam de suas casas e eram mortos.

A dança tem o poder de incorporar questóes sociais, políticas, estéticas e afetivas, os movimentos em dança formulam impressóes, concebem e representam experiências, projetam valores, sentidos e significados, revelam ainda os sentimentos, sensaçóes e emoçôes ${ }^{16}$. Vale aqui mencionar a dança moderna que no início do século XX, "privilegiava a emoção, a intuição, $\mathrm{o}$ inconsciente $\mathrm{e}$ visava a expressão direta da emoção, à descarga de sentimentos"16 (p. 46).

As cenas ${ }^{8}$ que se seguem mostram mais claramente as situações de não aceitação da diferença, onde a ginástica calistênica e movimentos de marcha buscavam igualar os corpos que deveriam ser 
obedientes e submissos, chegando aos extremos com cenas de mortes por esgotamento, fuzilamento e câmara de gás. Essas cenas proporcionaram uma reflexão, dos artistas no palco e das pessoas que assistiram o espetáculo, sobre como uma situação de preconceito pode levar às situaçóes como o Holocausto.

O Holocausto é hoje um conceito que tem sido deslocado do espaço e do tempo precisamente porque ele pode ser usado para dramatizar qualquer ato de injustiça, racismo ou crime cometido em qualquer lugar no planeta ${ }^{2}$ (p. 282).

Uma das bailarinas de 11 anos e cega relata em entrevista "eu como várias outras pessoas sofremos como prisioneiros", demonstrando que entende que encenou o sofrimento de uma prisioneira dos campos de concentração, apesar da pouca idade a fisionomia e tom de voz mostram a seriedade e consciência do seu papel9.

O coreógrafo do espetáculo relata que o Endless foi uma forma de discutir o Holocausto como uma situação atual, olhando-o como algo "Sem fim", com o desejo de que nunca mais acontecesse ${ }^{8}$.

A extensão universitária é um dos espaços que pode proporcionar a Educação para direitos humanos na Faculdade de Educação Física e Dança. Também pode ser um rico espaço de experiência, estudo e reflexão para a formação de professoras e professores mais inclusivos ${ }^{15}$.

Os depoimentos de dois professores de dança em formaçôes mostraram que a vivência no projeto de extensão com a dança inclusiva e o Endless proporcionaram reflexões significativas que poderão direcionar suas vidas profissionais. Uma estudante que foi responsável pedagógica pelo projeto do espetáculo fez um relato que traz reflexóes sobre o prazer de trabalhar com a dança que respeita diferentes corpos:

Tem uma coisa que me move muito, estar aqui nesse lugar trabalhando com esse público... eu vou dizer assim: a simplicidade, mas que não é uma simplicidade no sentido de diminuir, é algo tão natural que você se torna você mesma dentro de um lugar, não é aquele lugar onde você tem que se transformar para estar ali ${ }^{8}$.

Outro estudante do curso de dança e performance de outros grupos da cidade de Goiânia, disse dos preconceitos que existem na dança e o quanto a dança inclusiva e o espetáculo Endless transformou sua percepção em relação às pessoas com deficiência.
Em relação ao espetáculo acredito que eu me surpreendi muito com a questáo da proposta, com a questão... em relação a quem está dançando, quem está participando, porque a gente se surpreende com, não sei nem se falar com a capacidade, mas com a forma que todo mundo está se entregando, com a forma que todo mundo está se dedicando e com a forma que chega a mensagem para as pessoas, porque gente eu acho surpreendente. Na verdade, nós da dança temos a mania de subestimar a capacidade das outras pessoas e eu estou aprendendo que a gente não deve fazer isso ${ }^{8}$.

A coordenadora artística do projeto e do espetáculo em reportagem se às artes e a dança são inclusivas disse:

A arte realmente quebra padrōes e paradigmas, mas quando a gente pensa especificamente na dança que é no nosso caso, eu convido todas a pensarem que corpo é esse que dança, que padrōes estéticos são esses de corpo que vem nos apresentando na história da dança, e que corpos ficam invisíveis nesse lugar, ou porque não tem o padrão da dança clássica, ou não tem o padrão da dança moderna, então trazer esses corpos diferente é também mostrar uma outra possibilidade estética, ou seja outros padrốes de corpo ${ }^{10}$.

O relato de uma bailarina com obesidade, que é mãe de outra bailarina com síndrome de Down relata alguns momentos antes da estreia do espetáculo:

A expectativa está gigante, são várias pessoas que nunca pisaram no palco, estão ali numa representaçáo que tem um significado muito importante, a gente tem que sempre lembrar do Holocausto. $\mathrm{O}$ holocausto acontece a todo momento ${ }^{8}$.

Relata ainda:

As pessoas com deficiência também têm imaginação, também tem potencial, elas também têm condiçóes de interpretação, mas muitas vezes são infantilizadas, ou desprezadas, a arte é muito enriquecedora para as pessoas com deficiência, e a pessoa com deficiência enriquece a $\operatorname{arte}^{8}$.

Nesse projeto a deficiência e qualquer outra característica dos participantes foi respeitada com a acessibilidade necessária para sua participação plena 
e de qualidade. Dessa forma foi dado ênfase, não na deficiência, mas na eficiência dos participantes. E a maior atenção foi dada ao resultado performático que se buscava para atender aos objetivos do espetáculo, assim “o importante é o produto apresentado e não a questão da deficiência destas pessoas" $^{3}$ (p. 65).

\section{Imagens que falam e experiências que modificam}

Em todos os vídeos analisados nesse artigo as imagens dos ensaios e do espetáculo produzem mensagens e intençôes que podem significar mais que palavras. A vídeo-gravação como forma de análise de dados é carregada de vivacidade e dinamismo, que sofre interferência simultânea de múltiplas variáveis, permitindo análise de "acontecimentos fugazes e não-repetíveis que muito provavelmente escapariam a uma observação direta" ${ }^{17}$ (p. 423). O vídeo permite capturar o contexto das interaçóes, assim como permite que façamos repetidas revisóes, a fim de criar códigos para uma análise compreensiva do fenômeno como um todo ${ }^{18}$.

Tais análises puderam desvendar múltiplos fatores que ilustram a possibilidade do espetáculo aqui apresentado como instrumento de educação para direitos humanos. Entender e vivenciar o holocausto foi sem dúvida momento de muita aprendizagem, amadurecimento e reflexão para todos os 90 envolvidos no espetáculo, principalmente para as 60 pessoas que estiveram no palco encenando tais fatos, e possivelmente se estendendo às 2.100 pessoas que assistiram (FIGURA 2).

Essas imagens trazem algumas das cenas apresentadas rapidamente nos vídeos analisados. A primeira imagem traz uma cena que apresenta uma família cantando que não está ainda percebendo os horrores que já estavam acontecendo com sumiço e morte de pessoas na comunidade, na segunda imagem. Logo depois essa mesma família presencia assustada o fuzilamento de pessoas na sua frente. Dois fatos podem ser descritos nessas imagens que mostram a seriedade e entendimento dos fatos por parte das pessoas com e sem deficiência envolvidas nessa cena. Na primeira cena/imagem quando a família para de cantar e presencia o fuzilamento a adolescente com síndrome de Down chora em cena com lágrimas escorrendo em seu rosto, o que demonstra que ela estava realmente sensibilizada e triste com a encenaçáo e lembrança das mortes por fuzilamento durante o holocausto ${ }^{8-10}$.
Em uma das apresentaçóes do Endless foi dado prioridade para público proveniente de instituiçóes de pessoas com deficiência, entendendo-se que essas pessoas têm menos acesso à arte e como um projeto inclusivo não poderia excluir essas pessoas. Nessa sessão tínhamos na plateia pessoas com diferentes características, nas primeiras filas sentaram pessoas com deficiência intelectual, mas tínhamos também pessoas cegas, surdas, crianças de escolas, entre outras pessoas. A cena que está nos vídeos estudados e na segunda imagem, apresenta som de tiros, representando o fuzilamento, com alguns artistas caindo ao chão a cada som. É uma imagem/som impactante e cada pessoa da plateia reagia de uma forma. Algumas assustavam, outras paralisavam, outras riam, e outras agiam de formas diferentes. Assim as pessoas que assistiam faziam sons de susto ou de riso. Mas no palco, as pessoas com deficiência intelectual, cegas, surdas, sem deficiências, crianças, adolescentes, adultos, enfim com diversas características, continuaram concentradas, sérias, com fisionomia de sofrimento, entendendo seu papel de pessoas que estavam esperando serem mortas ${ }^{8-10}$.

A terceira imagem mostra as pessoas em roupas da mesma cor, sendo obrigadas ao som dos gritos dos soldados à marchar da mesma forma, na tentativa dos nazistas de apagar as diferenças. Da mesma forma os artistas agem de forma coerente ao seu papel em cena ${ }^{8-10}$.

A quarta cena, pode ser verificada em algum dos vídeos estudados, e representa um dos momentos mais cruéis do holocausto que são as câmaras de gás. A fisionomia de desespero, de agonia pela falta de ar, de horror, de impotência, entre outras coerentes com a situação, é possível de se ver e sentir nos movimentos corporais e faciais dos integrantes do espetáculo ${ }^{8-10}$.

A energia das cenas flutuou nas apresentaçóes e transbordam nas partes presentes nos vídeos analisados. É possível sentir a emoção encenada no momento do espetáculo por meio das cenas nos vídeos. Assim a educação para direitos humanos presente nesse projeto e espetáculo continua sendo propagada mesmo anos após o trabalho ${ }^{8-10}$.

A experiência com o Endless no Brasil, permitiu realizar um trabalho em dança onde os corpossujeitos não foram considerados como meras figuras ilustrativas, ou adereços para uma poética dançante "apelativa e ou comovente", mas sim, corpos que atuaram de forma singular, múltipla. 

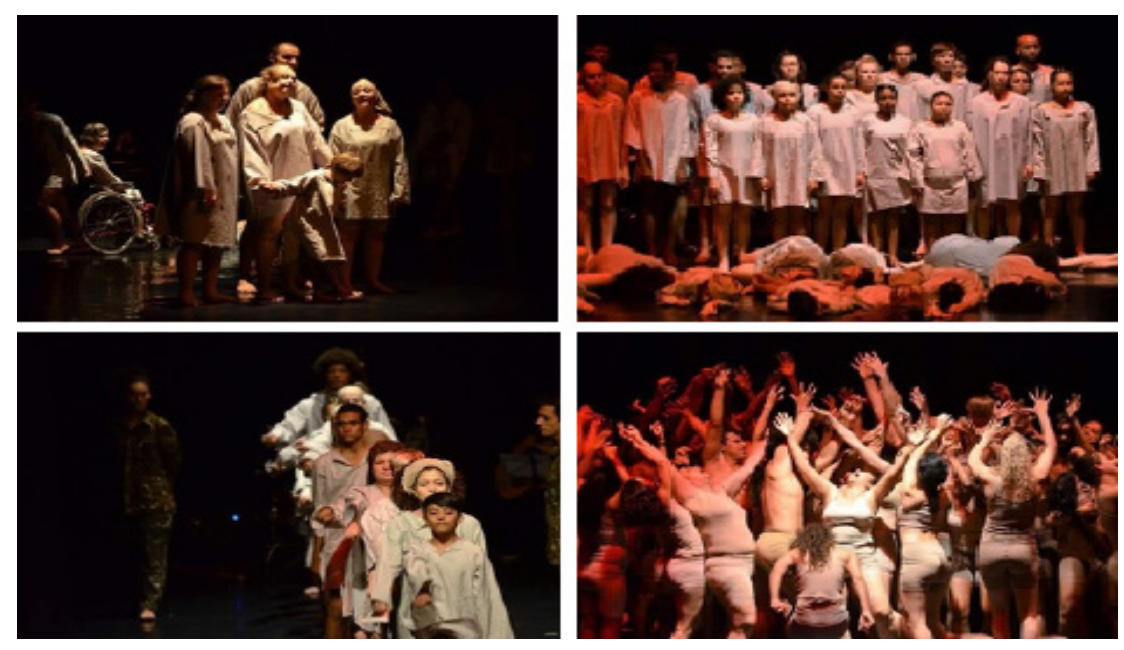

FIGURA 2 - Imagens do Espetáculo.

O espetáculo, permitiu, lançar um olhar com extremo respeito para a diferença e diversidade e que neste trabalho são percebidas como ferramentas metodológicas, potencializadoras da cena e da própria imagem corporal de cada intérprete.
A ótica da deficiência pelo viés da ineficiência e ou incapacidade e até mesmo classificatória, foi refutado, foi possível verificar a dança como possibilidade entender, discutir e encenar o Holocausto e de comprovar sua potência como Educação para Direitos Humanos.

\title{
Agradecimentos
}

Fundo de Arte e Cultura do Estado de Goiás, Brasil.

\begin{abstract}
DanceasapossibilityforHumanRightsEducation:Understanding, discussingandenacting theHolocaust.

This article aims to present dance as a possibility for human rights education. This is a qualitative research through descriptivecross-sectionalobservational studythrough documentaryanalysis of videos. Theobject of the study is to describe the process of education, preparation, awareness and realization of the Endless Show in Goiânia-Goiás. Through the results, it was possible to verify the power of university extension and dance as a form of education for human rights. Reports from dancers, choreographer and project coordinator were analyzed, as well as images from the rehearsal and the show. It was possible to verify, through the reports, that inclusive/decolonial danceand cultural accessibility, promoted changes in paradigms and awareness of the horrors of the Holocauto and Human Rights. The images of the rehearsals and spectacle also provided verification of the power of dance to raise awareness and awareness of the need for Human Rights. We concluded that the experience with Endless allowed those involved to participate in a singular, multiple way, with their efficiencies and disabilities. The show took a look at the respect for difference and diversity, proving the power of dance as Education for Human Rights.
\end{abstract}

KEYWORDS: Human rights; Dance; Diversity; Education. 


\section{Referências}

1. Declaração Universal dos Direitos Humanos. Assembleia Geral das Naçóes Unidas em Paris. 10 dez. 1948.

2. Levy D, Sznaider N A. institucionalização da moralidade cosmopolita: o Holocausto e os direitos humanos. Hist R. 2012;17(1):261-285.

3. Baldi N, Marques T, Nascimento D. Meia-volta na ciranda: reflexôes sobre decolonialidade na Dança. Interritórios Rev Educ Univ Fed Pernambuco. 2019;5(8).

4. Baldi NC, Oliveira JUD, Patias IT. Procedimentos artístico-pedagógicos em Dança a partir da decolonialidade e da autobiografia. Rev FUNDARTE. 2019;19(37):127:139.

5. Barral JHA. Dança inclusiva em contexto artístico análise de duas companhias [dissertação]. Lisboa: Universidade Técnica de Lisboa Faculdade de Motricidade Humana; 2002.

6. História do Grupo de Dança Diversus. Universidade Federal de Goiás [vídeo] [acesso 25 mai 2021]. Disponível em: https://youtu.be/ExZ79eVzCVA.

7. Dançando com a diferença. Apresentação promocional do espetáculo "ENDLESS", de Henrique Amoedo para o Dançando com a diferença, estreado no dia 11 de maio de 2012. Disponível em: https://www.youtube.com/watch?v=RaKb1xeAtI\&t=1s. Acesso em: 25 mai 2021.

8. Documentário Endless. Produção Julia Mariano. Goiânia: UEG. 2018. Disponível em: https://youtu.be/5S4ybppFCRg. Acesso em: 13 mai 2021.

9. Reportagem: dança inclusiva. Apresentação do espetáculo Endless. Produção TV Record. Disponível em: https://www. youtube.com/watch?v=cEgUJ1WReb4. Acesso em: 13 mai 2021.

10. TV UFG. Enredo cultural 2018: dançando com a diferença. Disponível em: https://www.youtube.com/ watch?v=fyVvl4woygI. Acesso em: 13 mai 2021.

11. Bardin L. Análise de conteúdo. Lisboa: Ediçóes 70, 1977.

12. Dalla Déa VHS, Cunha MV, Nascimento OAS, Lima AF, Lima MD. Inclusão de pessoas com deficiência nos projetos de extensão de práticas corporais da Universidade Federal de Goiás. Pensar Prática. 2013;16(4):9561270.

13. Silveira SR, Freudenheim AM, Bassi P, Oliveira JA. Núcleo de Direitos Humanos da Escola de Educação Física e Esporte da USP: uma perspectiva educativa. Rev Bras Educ Fís Esporte. 2020;34(nesp):1-9.

14. Ferreira CR, Zingano EM. A arte com deficientes auditivos. Rev Maiêutica Arte Cult. 2013;1(1).

15. Dalla Déa VHS, Moura J, Santander C. Universidade enquanto formadora de profissionais e professores preparados para a inclusão. In: Machado VF, Borges RMR, Santos LR, organizadores. Direitos Humanos: inclusão. Goiânia: CIAR/ UFG, 2016, p. 35.

16. Dantas M. Dança: o enigma do movimento. Porto Alegre: Ed Universidade/UFRGS, 1999.

17. Sadalla A M, Larocca P. Autoscopia: um procedimento de pesquisa e de formação. Educ Pesq. 2004;30(3):419-433.

18. Garcez A, Duarte R, Eisenberg Z. Produção e análise de vídeo-gravações em pesquisas Qualitativas. Educ Pesq. 2011;37(2):249-262.

\begin{tabular}{r|c} 
ENDEREÇO & \\
Vanessa Helena Santana Dalla Déa & \\
Rua 1A, Quadra 19, Casa 2 & Submetido: 28/05/2021 \\
Chácara Recreio Samambaia & Aceito: 02/06/2021 \\
13741-340 - Goiânia - GO - Brasil & \\
E-mail: vanessasantana@ufg.br &
\end{tabular}

